\title{
O PAPEL DA EDUCAÇÃO AMBIENTAL NAS AÇÕES DE COMBATE AS MUDANÇAS CLIMÁTICAS
}

Emanuel Mateus da Silva ${ }^{1}$

Resumo: A presente pesquisa apresenta uma abordagem teórica, bem como um breve histórico sobre o tema: "Educação Ambiental", desafios e perspectivas de sua aplicabilidade no âmbito escolar. O objetivo deste trabalho é mostrar a importância de sua efetivação e obrigatoriedade do ensino de Educação Ambiental em todos os níveis de ensino e despertar no indivíduo a conscientização e ideal de conservação e preservação da natureza, para assim diminuir os impactos ambientais. Justificando-se também por sua efetivação não como disciplina de fato, mas como tema transversal e o refletir criticamente sobre essa ideia. Nessa perspectiva são apresentadas ideias de alguns autores como LE PRESTRE (2000), JORA (2006) buscando em linhas gerais fortalecer ainda mais o estudo em questão, bases teóricas imprescindíveis para o desenvolvimento do trabalho. O caminho metodológico se dá por meio de leituras literárias, cartilhas, artigos, pesquisas na internet, onde se configura uma pesquisa qualitativa. Portanto o trabalho em questão serve de suporte teórico para possíveis estudos acerca do tema abordado e um novo olhar sobre os impactos ambientais causados pelo aquecimento global, levando o homem a refletir e a buscar maneiras eficazes de diminuição dos efeitos causados por esse fenômeno, para assim viver melhor e com qualidade de vida em sociedade.

Palavras-chave: Educação Ambiental; Aquecimento Global; Desafios.

${ }^{1}$ Especialista em Gestão Escolar pela Universidade Federal do Ceará - UFC, professor da Rede Estadual de Ensino (SEDUC/CE). E-mail: emanuel.mateus23@gmail.com

Revbea, São Paulo, V. 14, No 2: 388-397, 2019. 


\section{Introdução}

O grande problema enfrentado pela sociedade há muito tempo é o ciclo de alterações das mudanças climáticas. Por esse motivo, busca-se em linhas gerais fomentar no aluno, através de estudos e pesquisas o interesse pela Educação Ambiental no ambiente escolar, como também compreender o papel dessa educação e sua importância, para assim junto com os demais envolvidos no processo educativo e a comunidade escolar discutir e propor ações que venham a minimizar os impactos ambientais na vida social.

Por essa questão, pensar uma Educação Ambiental, como disciplina, não, mas como tema transversal são razões fundamentais para refletir criticamente o porquê da inserção dessa temática e sua importância no âmbito educacional. Dessa forma essa ação é parte imprescindível para o fortalecimento e efetivação de uma educação também voltada para o enfrentamento das questões ambientais que assolam e ceifa de maneiras arrasadoras a vida humana.

Com relação aos passos percorridos nesta pesquisa, fez-se necessário, várias pesquisas, leitura literária em livros, revistas, artigos científicos, leituras na internet sobre o tema: Educação Ambiental, contexto histórico, concepções, desafios e perspectivas da Educação Ambiental nas ações de combate as mudanças climáticas.

Assim, acreditar no poder que a educação exerce sobre o homem é pensar e enxergar além das nossas possibilidades reais, acreditando que sempre se pode ir mais além. É por meio dela que se pode enfrentar os riscos provenientes das mudanças climáticas, aprender e apresentar meios de prevenções diante de catástrofes, rever e propor novas ações voltadas à políticas ambientais, onde também faz-se necessário mudanças nas formas de pensar e estilo de vida da sociedade, na busca de instituir políticas públicas de enfrentamento a esses problemas.

\section{Marcos histórico da Educação Ambiental}

Há tempos se vem pensando em Educação Ambiental numa perspectiva de inclusão dessa temática na Base Curricular do Ensino Regular e mais tarde no Ensino Superior. Como algo desafiante para amenizar os problemas sociais provenientes do aquecimento global. Tal fato não se dá somente numa perspectiva do que venha a ser certo ou errado diante desses problemas, mas não na complexidade que esse fenômeno é nos âmbitos: social, político, econômico e ambiental. Assim, faz-se necessário um levantamento de acontecimentos internacionais e nacionais que influenciaram a EA mundial.

Referenciar a Conferência de Estocolmo ou Conferência das Nações Unidas sobre o Meio Ambiente Humano, Suécia (1972) como marco importante no processo preservação do meio ambiente, tinha como foco amenizar o problema provocado pelo embate homem $\mathrm{x}$ natureza, vista como primeira reunião voltada para tais problemas, buscando assim criar um novo 
pensamento, 0 de agir conscientemente diante da existência desses fenômenos, como forma de tomar medidas e criar estratégias de prevenção imediatas.

Segundo Le Prestre (2000), a conferência foi realizada para atender quatro fatores que foram influência à época:

1. Aumento e importância da comunidade científica, que começavam a questionar sobre o futuro do planeta, as mudanças climáticas e sobre a quantidade e qualidade da água.

2. Aumento da exposição, pela mídia, de desastres ambientais (marés negras, desaparecimento de territórios selvagens, modificações na paisagem), gerando um maior questionamento da sociedade acerca das causas e soluções para tais desastres.

3. Crescimento desenfreado da economia, e consequentemente das cidades, sendo que estas cresceram sem nenhum planejamento para o futuro.

4. Outros problemas ambientais, como chuvas-ácidas, poluição do Mar Báltico, grandes quantidades de metais pesados e pesticidas.

Tal evento foi importante porque mostrava os primeiros passos e a vontade de colocar o homem e a natureza em total equilíbrio, o que para muitos parece e é difícil de acontecer, uma vez que o homem é um ser consumista e egocêntrico, cabendo assim criar uma rede de conscientização e preservação dos recursos naturais e mostrar que a solução e mudanças para as catástrofes ambientais são responsabilidades de todos agindo para um bem comum: um meio ambiente saudável e sustentável.

Por outro lado, por recomendações da Conferência de Estocolmo, no ano de 1975 na cidade de Belgrado (ex-lugoslávia) foi realizado o Seminário de Educação Ambiental, onde ao final desta conferência foi criado o documento conhecido como "Carta de Belgrado" primeiro documento oficial dedicado integralmente à Educação Ambiental. A Carta de Belgrado 1975 afirmou textualmente:

Governos e formuladores de políticas podem ordenar mudanças e novas abordagens para o desenvolvimento, podem começar a melhorar as condições de convívio do mundo, mas tudo isso não passa de soluções de curto prazo, a menos que a juventude mundial receba um novo tipo de educação. Esta implicará um novo e produtivo relacionamento entre estudantes e professores, entre escolas e comunidades, e entre o sistema educacional e a sociedade em geral. 
Esse texto leva a concluir que a mudança está no processo educacional, ou seja, os passos para a transformação, para o agir, para o conscientizar-se dos problemas ambientais está em primeiro lugar na escola, e para isso faz-se necessário um maior investimento nesse processo, políticas públicas ambientais efetivas, formulação de projetos, criar espaços que favoreçam esse pensar e agir sobre essas questões e vendo teoricamente como um documento norteador de uma Educação Ambiental de âmbito interdisciplinar e transdisciplinar, traduzindo a ideia de que é uma temática que perpassa por todas as áreas do conhecimento e vista como um dos elementos mais críticos para que se possa combater rapidamente a crise ambiental mundial. Cabe neste momento mencionarmos parte da Declaração de Ahmadabad (apud GADOTTI, 2008), quando fala que por meio da educação podemos aprender a prevenir e resolver conflitos, respeitar a diversidade cultural, criar uma sociedade cuidadosa e viver em paz.

Outro importante evento foi a Conferência de Tbilisi, antiga União Soviética, 1997, realizado em parceria com a UNESCO e o Programa de Meio Ambiente da ONU - PNUMA foi deste encontro que saíram as definições, objetivos e princípios para a Educação Ambiental no mundo.

Dessa forma ressalta-se a importância do processo educativo como passo importante na orientação para a resolução de problemas ambientais com enfoque interdisciplinar, processo este que se efetiva pela participação ativa individual e coletiva em sociedade. A Conferência de Tbilisi tem esses objetivos:

a)Consciência: ajudar os grupos sociais e os indivíduos a adquirirem consciência do meio ambiente global e ajudar-Ihes a sensibilizarem-se por essas questões;

b)Conhecimento: ajudar os grupos sociais e os indivíduos a adquirirem diversidade de experiências e compreensão fundamental do meio ambiente e dos problemas anexos;

c) Comportamento: ajudar os grupos sociais e os indivíduos a comprometerem-se com uma série de valores, e a sentirem interesse e preocupação pelo meio ambiente, motivando-os de tal modo que possam participar ativamente da melhoria e da proteção do meio ambiente;

d)Habilidades: ajudar os grupos sociais e os indivíduos a adquirirem as habilidades necessárias para determinar e resolver os problemas ambientais;

e)Participação: proporcionar aos grupos sociais e aos indivíduos a possibilidade de participarem ativamente nas tarefas que têm por objetivo resolver os problemas ambientais. 
Assim com esses objetivos pretende-se induzir o homem há um processo de transformação, a informação e a sua adequação, para que assim mude a sua relação com o meio ambiente e assim ajudar a minimizar os impactos ambientais respectivamente.

Tal conferência não foi suficiente para minimizar os impactos ambientais, ao contrário isso se agravou cada vez mais, apesar da proposta de orientar as práticas pedagógicas, fazer refletir sobre o problema em questão em quase todo o mundo, levou a UNESCO-UNEP/IEEP dez anos mais tarde a organizar um congresso com o objetivo de revisar as políticas de Educação Ambiental e traçar planos para a década de 90 .

Congresso Internacional de Educação e Formação, Moscou, 1987, congresso este que reafirmou os princípios da conferência de Tbilisi partindo da ideia de que os objetivos da Educação Ambiental têm que ser definidos levando-se em conta a realidade social, econômica e ecológica da sociedade. Assim como a necessidade de criar recursos e estratégias em longo prazo, tendo em vista que os problemas não se resolvem de imediato, além de ter como objetivo de tornar-se um verdadeiro plano de ação e inclusão da EA em todos os níveis de ensino e o conceito de desenvolvimento sustentável.

Por sua vez a Conferência Internacional sobre o Meio Ambiente e Desenvolvimento, Rio de Janeiro, 1992 parte do princípio de respeito aos interesses de todos e se proteja a integridade do sistema ambiental e o desenvolvimento mundial, isso se dá pelo fato da diversidade cultural, social, política e econômica do mundo, ou seja, o mundo não é homogêneo, devem-se respeitar as peculiaridades de cada país. Parte também da declaração e recomendações de Tbilisi, em que na prática propões uma reorientação da Educação Ambiental e um novo olhar sobre o termo desenvolvimento sustentável, de um lado a dimensão política e ética e por outro lado o olhar do gerenciamento sustentável dos recursos naturais. Assim essa ideia de desenvolvimento sustentável tem sido muito discutida, reivindicada e com grande enfoque pela agenda 21 , como forma de minimizar ou remediar os impactos ambientais do planeta.

Em consonância com os acordos firmados no Rio-92, no ano de 2003 o Governo Brasileiro lança para consulta pública o Programa Nacional de Educação Ambiental, tendo como missão estimular a ampliação e o aprofundamento da Educação Ambiental em todos os municípios, setores do país e sistemas de ensino, contribuindo para a construção de territórios sustentáveis e pessoas atuantes e felizes (BRASIL, 2003, p. 23). Vale salientar que o Programa Nacional de Educação Ambiental, é baseado na Lei 9.795/1999 que institui a Política Nacional de Educação Ambiental.

Assim, fazer um breve levantamento histórico da Educação Ambiental é de fundamental importância para que entendamos a real necessidade de se discutir os problemas ambientais causados pela má formação sociocultural do homem, como também da efetivação em todos os níveis e modalidades de ensino, visando colo colocar em prática as discussões e acordos assinados em 
eventos sobre o meio ambiente, haja vista que essa educação representa, sobretudo, uma reflexão política sobre a ação do homem com a natureza e vice-versa, para assim minimizar os impactos ambientais.

\section{Desafios e perspectivas da Educação Ambiental no âmbito escolar}

Instituir a Educação Ambiental em todos os níveis de ensino ainda é um grande desafio, considerando o pouco tempo e devida importância que as escolas dão a tal temática na sala de aula. Acreditamos que tal feito se dar por duas vertentes, a primeira é sobre a não afirmação da Educação Ambiental enquanto disciplina, a lei 9.795/99 no seu Art. 10, § 1ㅇ A Educação Ambiental não deve ser implantada como disciplina específica no currículo de ensino (BRASIL, 1999). E a outra se dá porque ainda não foi de fato efetivado no homem a consciência e a reflexão de que os problemas ambientais são prejudiciais ao mesmo, tento em vista que é somente pela educação que se pode mudar essa realidade. E como diz Kant (apud NISKIER, 2001, p 156):

O homem só pode tornar-se homem pela educação. Ele não é mais do que aquilo que a educação faz dele. É preciso notar bem que o homem só é educado por homens e por homens que igualmente foram educados.

Dessa forma acredita-se que é pelo processo de ensino que o homem adquire autonomia, e é o meio pelo qual ele vai buscar o conhecimento, entender o seu papel na sociedade e perceber a Educação Ambiental como processo contínuo que visa formar uma consciência ecológica em cada cidadão bem como a sua atuação, reflexão e devida aplicação dos conceitos e preceitos dessa educação no dia a dia respectivamente.

A Lei brasileira que trata sobre a Educação Ambiental mostra-se de fato ambígua e faz com que as escolas, instituições de ensino deixem de considerála como algo importante e essencial para a vida em sociedade.

Como dito anteriormente, o desafio é a não obrigatoriedade da Educação Ambiental no currículo, pois a lei não prevê a possibilidade de inclusão da disciplina na grade curricular. Veja o que diz a lei que dispõe sobre a Educação Ambiental:

Art. 2o A Educação Ambiental é componente essencial e permanente da educação nacional, devendo estar presente, de forma articulada, em todos os níveis e modalidades do processo educativo, em caráter formal e não-formal. (BRASIL, 1999) 
Mas adiante, no seu Art. $10^{\circ}$ ela descreve que,

A Educação Ambiental será desenvolvida como uma prática educativa integrada, contínua e permanente em todos os níveis e modalidades do ensino formal.

$\S 1^{\circ}$ ela diz que, a Educação Ambiental não deve ser implantada como disciplina específica no currículo de ensino. (idem, 1999).

Ao mesmo tempo em que demonstra a importância de se trabalhar a EA, em seguida a lei impossibilita que esta seja incorporada na grade curricular do ensino. Ficando a cargo dos professores das áreas de humanas e ciências da natureza incorporá-la em seus conteúdos básicos de ensino, principalmente, nas disciplinas de Geografia e Biologia.

Contudo, espera-se que os órgãos de ensino exijam a obrigatoriedade e inclusão da Educação Ambiental como disciplina, a fim de dar maior enfoque aos problemas ambientais, trabalhar de maneira efetiva o conceito de EA, bem como a pesquisa e o engajamento individual e coletivo da sociedade na busca de políticas públicas e melhoramento dos impactos ambientais.

Outro desafio que consideramos pertinente atualmente é conseguir acoplar a Educação Ambiental a Educação para o Desenvolvimento Sustentável. Nesse sentido, a partir da década de 90, a temática desenvolvimento sustentável com mais ênfase, passou a ser um motivo de discussão quando o assunto é mudança na qualidade da educação e de vida do Planeta.

O problema torna-se ainda mais graves quando se sabe que dificuldade em torno do sistema ambiental, com a desconsideração da participação ativa dos estudantes ou uma noção ambígua do que seja desenvolvimento sustentável. Nesse sentido, essa é uma das principais queixas de estudiosos sobre as questões ambientais, em que muitos indivíduos não sabem reconhecer o verdadeiro conceito do que ser e ter uma vida sustentável. É preciso que tenhamos a noção de que não há desenvolvimento sustentável sem uma sociedade sustentável e, esta, depende de uma educação sustentável. Portanto, o desenvolvimento sustentável apresenta um forte componente educativo que depende do desenvolvimento de uma consciência ecológica, que depende, por sua vez, da educação.

Essa noção deturpada em que se apresenta a questão do desenvolvimento sustentável faz a nosso ver com que a Educação para o Desenvolvimento Sustentável (EDS) e a Educação Ambiental, de fato não aconteça dentro da sociedade, sobre isso os autores afirmam que: 
A ambiguidade da noção de desenvolvimento sustentável reside em que, ao mesmo tempo que se aceita a existência de limites aos modos de vida que não sejam compatíveis com os princípios ecológicos, mantém-se a crença no crescimento ou desenvolvimento (...) para satisfazer a necessidade humana. A ela junta-se a indefinição do conceito de necessidade (LUFFIEGO GARCIA; RABADAN VERGARA, 2000, p. 474)

Logo se faz necessário e por meio da educação desmistificar essa noção deturpada, trabalhar o real sentido e objetivo do que é desenvolvimento sustentável, em que o ideal seria renovar primeiro a cultura para reestruturar a produção de consumo, criar no indivíduo a consciência de consumir somente o necessário, quando sugere de fato qualidade ao invés de quantidade, levando também as escolas e sociedade em geral a trabalhar com a ideia de redução da matéria-prima e produtos, aumentando a reutilização para assim diminuir cada vez mais os danos causados ao meio ambiente.

Acreditamos assim como Gadotti que o desenvolvimento sustentável tem um componente educativo formidável: a preservação do meio ambiente depende de uma consciência ecológica e a formação da consciência depende da educação.

É necessário também o fortalecimento de políticas públicas em relação aos problemas ambientais, o planeta grita por socorro há tempos, mas políticas adequadas às necessidades e realidade de cada região, de cada povo. Para assim, fortalecer a ideia de cidadania, preservar e resgatar a identidade de determinadas culturas, dando suporte, autonomia para uma sociedade mais justa, igualitária, solidária e inclusiva quanto as questões ambientais respectivamente.

Sensibilizar, refletir, conscientizar, conservar, preservar são verbos de ação imediata, ou seja, é urgente e necessário cultivar no homem o quão a natureza é importante para a sobrevivência humana e animal e isso se dá de forma efetiva por meio da educação. Como diz Jora (2006, p.191):

a promoção da Educação Ambiental, como processo político e pedagógico, direcionada à mobilização do exercício da cidadania, permite amealhar conhecimentos, valores e habilidades, para se reverter este pavoroso quadro de desigualdade social e para (re)aprender a complexidade das variáveis ambientais numa visão integrada de mundo, contribuindo para fomentar ações emancipatórias críticas e sensibilizadoras de conservação e preservação ambiental".

Portanto, conscientizar-se de que a nossa vida depende da vida do meio ambiente já é um passo importante para a promoção e integração curricular da Educação Ambiental em todos os níveis e modalidades de ensino. Dessa forma 
fica mais fácil pregar a idéia de conservação e preservação ambiental ao homem de modo a fazê-lo refletir e mudar seus comportamentos em relação as suas ações contrárias a vida da natureza. E como a educação é o principal meio e que é através dela que mudamos o mundo, prega-se que o cuidado com o meio ambiente exige do homem ultrapassar fronteiras e gerações, pois requer dele agora o dever que lhe é atribuído de cuidar e zelar pelo bem maior que é a vida, bem como o de resguardar o direito a vida das gerações futuras.

\section{Considerações finais}

Instituir a Educação Ambiental no âmbito escolar de forma obrigatória na grade curricular em todos os níveis de ensino é uma forma de disseminar a ideia de preservação e conservação do meio ambiente para assim diminuir os impactos causados pelo aquecimento global, acreditando assim que é por meio da educação que podemos transformar o mundo.

Muitos são os desafios enfrentados acerca da Educação Ambiental, porém os que nos chamam a atenção é a obrigatoriedade da EA na grade curricular, perpetuar a noção de desenvolvimento sustentável dissociando da ideia de crescimento econômico para diminuir os impactos ambientais e o conscientizar-se de que respeitar o meio ambiente é respeitar a vida e repassar essa ideia para as futuras gerações. Vale ressaltar que a partir do momento em que foi conceituado de fato o que é desenvolvimento sustentável este passou a fazer parte da Educação Ambiental e formalizando-se em Educação para o Desenvolvimento Sustentável.

A Educação Ambiental é um importante mecanismo para atingir a sustentabilidade, para transformar o pensamento humano, fazê-lo pensar, refletir e conscientizar-se da sua importância na sociedade e assim dissipar também por meio da escola e no alunado a ideia de preservação e conservação ambiental na diminuição dos impactos sobre o meio ambiente e garantir cada vez mais qualidade de vida agora e para as vida futura.

Almeja-se que este artigo sirva de subsídio teórico para outras pesquisas, análises e reflexões acerca da temática abordada, na perspectiva de um novo olhar para a Educação Ambiental, sua obrigatoriedade e efetivação como disciplina permanente na grade curricular em todos os níveis de ensino. E acreditar que é possível transforma essa realidade catastrófica que a sociedade está inserida, pois a educação é a principal arma de transformação e é por meio dela que o homem vai mudar essa realidade e buscar um meio ambiente ecologicamente sadio e equilibrado.

Pois, "da minha aldeia vejo quanto da terra se pode ver no Universo... Por isso a minha aldeia é tão grande como outra terra qualquer. Porque eu sou do tamanho do que vejo e não do tamanho de minha altura" (Fernando Pessoa). 


\section{Referências}

BRASIL, Ministério do Meio Ambiente. Programa Nacional de Educação Ambiental - ProNEA. Brasília, 2003. Disponível em: $<$ http://www.planalto.gov.br/ccivil 03/leis/19795.htm>, acesso em 06 de maio de 2019.

BRASIL, Câmara dos Deputados. Lei no 9.795 de 27 de Abril de 1999 Política Nacional de Educação Ambiental. Brasília, 1999.

CARTA DE BELGRADO. Disponível em: <http://www.meioambiente.pr.gov.br/ modules/conteudo/conteudo.php?conteudo $=71>$, acesso em 06 de maio de 2019.

CONFERÊNCIA DE TIBLISI. Disponível em: <http://www.portaleducacao .com.br/biologia/artigos/27425/conferencia-de-tbilisi-1977:, acesso em 06 de maio de 2019.

LUFFIEGO GARCIA, M.; RABADÁN VERGARA, J.M. La evolución Del concepto de sostenibilidad y su introdución en la enseñanza. Enseñanza de las ciências, España, 2000.

GADOTTI, M.. Pedagogia da terra: Ecopedagogia e educação sustentável. Perspectivas atuais da Educação. Artes Médicas, 1999.

JORA, M.A. Precaução e Educação Ambiental na sociedade de risco. Direito e Educação. Porto Alegre: UFRGS, 2006.

LE PRESTE, P. Ecopolítica Internacional. São Paulo: Senac, 2000.

NISKIER, A. Filosofia da Educação uma visão crítica. São Paulo: Loyola, 2001. 